\title{
Reguladores vegetais e substratos no enraizamento de estacas de erva-baleeira (Varronia curassavica Jacq.)
}

\author{
MENDES, A.D.R. ${ }^{1 *}$; LACERDA, T.H.S. ${ }^{2}$; ROCHA, S.M.G. ${ }^{3}$; MARTINS, E.R. ${ }^{4}$ \\ ${ }^{1}$ Universidade Federal de Minas Gerais/Campus Montes Claros, Av. Universitária, 1.000, Montes Claros, MG, \\ CEP: 39.404-547, are.dani@hotmail.com. ${ }^{2}$ Universidade Federal de Minas Gerais/Campus Montes Claros, Av. \\ Universitária, 1.000, Montes Claros, MG, CEP: 39.404-547, talles1992@hotmail.com. ${ }^{3}$ Universidade Federal \\ de Minas Gerais/Campus Montes Claros, Av. Universitária, 1.000, Montes Claros, MG, CEP: 39.404-547, \\ sofiamaria.r@hotmail.com. ${ }^{4}$ Universidade Federal de Minas Gerais/Campus Montes Claros, Av. Universitária, \\ 1.000, Montes Claros, MG, CEP: 39.404-547, ernane.ufmg@gmail.com
}

RESUMO: A erva-baleeira, espécie medicinal anti-inflamatória, pode ser propagada por sementes, no entanto, o desenvolvimento de métodos eficientes para a propagação vegetativa possibilitará a uniformidade nas populações e a clonagem de plantas de interesse quanto aos aspectos agronômico e de composição química. O presente trabalho objetivou avaliar os efeitos do ácido naftaleno acético (NAA) e do ácido indolbutírico (IBA) e de diferentes substratos no enraizamento de estacas semi-lenhosas de erva-baleeira. Os experimentos foram conduzidos em casa de vegetação em Montes Claros em delineamento inteiramente casualizados. Para o experimento teste da influência das auxinas, as estacas foram submetidas a tratamentos com NAA e IBA nas concentrações de 0,500,1000, 2000, 3000 e $4000 \mathrm{mg} \mathrm{L}^{-1}$, e para o experimento dos substratos, cinco substratos foram avaliados (vermiculita expandida + casca de arroz parcialmente carbonizada (proporção de 1:1); vermiculita expandida; substrato orgânico comercial para hortaliça (Tropstrato HT $®$ ); areia; solo + compostagem (proporção de 1:1)). Após 90 dias, para ambos os experimentos, foram avaliadas porcentagem de estacas enraizadas, de estacas mortas, de estacas vivas com calos, de estacas mortas com calos, número de raízes formadas por estaca e comprimento das três maiores raízes $(\mathrm{cm})$. O regulador vegetal ideal para o enraizamento da espécie é o IBA, na concentração de $2.000 \mathrm{mg} \mathrm{L}^{-1}$, sendo que o NAA não é recomendado para a indução radicial em estacas erva-baleeira. O substrato vermiculita com casca de arroz carbonizada na proporção de 1:1 proporcionou maior porcentagem de enraizamento nas estacas da erva-baleira que o substrato solo + compostagem (1:1), os demais substratos não diferenciaram entre si.

Palavras-chave: plantas medicinais, estaquia, auxina, propagação vegetativa.

ABSTRACT: Growth regulators and substrates on rooting of Varronia curassavica Jacq. The Varronia curassavica Jacq., black sage, is an anti-inflammatory medicinal species that can be propagated by seed; however, the development of efficient methods for vegetative propagation will enable uniformity in the populations and cloning of plants of interest regarding the agronomic aspects and chemical composition. The aim of this study was to assess the effects of the naphthalene acetic acid (NAA) and indole butyric acid (IBA) and different substrates on the rooting of semi-hardwood cuttings of black sage. The experiments were conducted in a greenhouse at Montes Claros, in the State of Minas Gerais, Brazil, as a randomized complete design. For the experiment to test the influence of auxin, the cuttings were subjected to treatments with NAA and IBA at the concentrations of 0,500, 1000, 2000, 3000 and $4000 \mathrm{mg} \mathrm{L}^{-1}$, and for the experiment with substrates, five substrates were evaluated (expanded vermiculite + carbonized rice husk (1:1); expanded vermiculite; commercial organic substrate for vegetable (Tropstrato ${ }^{\circledR}$ $\mathrm{HT}$ ); sand; soil + compost (1:1)). After 90 days, in both experiments, we evaluated the rooting percentage of cuttings, dead cuttings, live cuttings with callus, dead cuttings with callus, number of roots per cutting and length of the three longest roots $(\mathrm{cm})$. The best plant growth regulator for the rooting of the species is the IBA at a concentration of $2.000 \mathrm{mg} \mathrm{L}^{-1}$, and the NAA is not recommended for the induction of roots in cuttings of black sage. Vermiculite with carbonized 
rice husk in the ratio of $1: 1$ showed greater percentage of rooting in cuttings of black sage than soil + composting (1:1); other substrates did not differ among themselves.

Keywords: medicinal plants, cuttings, auxin, vegetative propagation.

\section{INTRODUÇÃO}

Varronia curassavica Jacq., (Boraginaceae) possui sinonímia científica Cordia verbenacea DC. sendo conhecida popularmente como erva-baleeira. Conhecida como planta de crescimento vigoroso, cresce espontaneamente em áreas abertas de pastagens, beira de estradas e terrenos baldios, onde é considerada planta daninha. A espécie é encontrada desde a América Central até o sul do Brasil, sendo característica da restinga litorânea do Ceará até o Rio Grande do Sul (Lorenzi \& Matos, 2008).

Suas folhas aromáticas possuem propriedades medicinais com ação anti-inflamatória, antiulceral, antimicrobiana, antirreumática, analgésica e com propriedades tônicas (Carvalho et al., 2004; Michielin et al., 2009). O primeiro fitoterápico produzido no Brasil foi desenvolvido a partir do óleo essencial de folhas da erva-baleeira, o Acheflan ${ }^{\circ}$. O princípio ativo desse fitoterápico está relacionado a dois sesquiterpenos, o alfahumuleno e o trans-cariofileno, os quais inibiram significativamente a expressão da Ciclooxigenase-2 e óxido nítrico (Fernandes et al., 2007, Passos et al., 2007, Medeiros et al., 2007).

Devido às propriedades terapêuticas da erva-baleeira existe grande interesse na ampliação de estudos sobre a planta, principalmente estudos voltados para a seleção de genótipos interessantes quanto aos seus aspectos agronômicos e a sua composição química (Vaz et al., 2006). Visando a produtividade comercial dessa espécie medicinal, são necessários estudos de métodos eficientes de propagação.

Aerva-baleeira é propagada, principalmente, por meio de sementes, esse processo de propagação é um processo demorado de multiplicação e também apresenta grande variabilidade com relação à produção de metabólitos, devido a segregação genética, o que torna difícil o plantio comercial uniforme de genótipos com alta capacidade de síntese desses metabólitos. A propagação vegetativa por meio do uso de estacas é a técnica de multiplicação de plantas com maior viabilidade econômica para o estabelecimento de plantio comercial, pois permite com menor custo, a multiplicação de genótipos de interesses.

Algumas espécies apresentam limitações na obtenção de mudas por propagação vegetativa, principalmente devido à dificuldade de enraizamento das estacas. Para as espécies de difícil enraizamento, o uso dos reguladores vegetais tem sido uma forma de aumentar ou proporcionar o enraizamento (Alcantara et al., 2010). As auxinas são uma classe de reguladores vegetais envolvidos em muitos aspectos do crescimento e desenvolvimento de plantas. Quando aplicada em órgãos isolados, a auxina, dependendo de sua concentração, pode aumentar a resposta rizogênica até certo ponto, após o qual ocorre efeito inibitório (Goulart et al., 2008). O IBA (ácido indolbutírico) e o NAA (acético naftalenoacético) têm se revelado como os mais eficientes na indução de primórdios radiciais visando o enraizamento (Camargo \& Vieira, 2001).

Lameira et al. (1997) estudando a propagação de erva-baleeira por meio do enraizamento de miniestacas com $10 \mathrm{~cm}$ de comprimento, com o plantio diretamente no substrato (sem imersão) ou com imersão de sua base em soluções contendo 250, 500 e 750 mg/l de ácido indolbutírico adicionado de $100 \mathrm{mg} / \mathrm{l}$ de ácido bórico e $20 \mathrm{~g} / \mathrm{l}$ de sacarose, durante 24 horas, verificaram que a presença do regulador vegetal influenciou positivamente na formação do sistema radicial. Dada a escassez de informação sobre o comportamento das auxinas no enraizamento de erva-baleeira, são necessários estudos visando ampliar o conhecimento na área.

Além do balanço hormonal, o enraizamento das estacas está relacionado à espécie a ser cultivada, bem como às condições do ambiente em que são conduzidas, tais como substrato, umidade, temperatura, irrigação e luminosidade (Fachinello et al., 2005). O substrato é o meio onde as raízes se desenvolvem, devendo ser poroso, bem drenado, homogêneo, isento de patógeno, ter baixa densidade e viabilidade econômica. $O$ material deve permitir que a base da estaca obtenha bom suprimento de água e ao mesmo tempo boa aeração (Bitencourt et al., 2010). Os estudos dos diferentes substratos para a propagação vegetativa de erva-baleeira são de fundamental importância para produção e comercialização.

$\mathrm{Na}$ busca de técnicas de propagação vegetativa mais eficiente de erva-baleeira, o objetivo deste trabalho foi avaliar as melhores concentrações de duas auxinas (ácidos naftaleno acético e ácido indolbutírico) e de substratos no enraizamento de estacas semi-lenhosas de erva-baleeira. 


\section{MATERIAL E MÉTODO}

Os experimentos foram conduzidos em casa de vegetação no Instituto de Ciências Agrárias da Universidade Federal de Minas Gerais (ICA/ UFMG), em Montes Claros-MG, entre os meses de janeiro a setembro de 2012. As estacas caulinares da erva-baleeira foram confeccionadas da parte mediana de ramos semi-lenhosos coletados de uma planta matriz com dez anos de idade, do Horto Medicinal do ICA/UFMG, localizado no município de Montes Claros-MG. A multiplicação de apenas uma matriz visa a seleção de genótipo com características agronômicas e químicas desejáveis para o estabelecimento de plantio comercial.

O material vegetal foi coletado no período da manhã, entre as 8 e 10 horas, sendo que, no dia da instalação dos experimentos e durante o preparo das estacas, estas foram mantidas em recipientes com água para evitar a desidratação. As estacas foram padronizadas com $12 \mathrm{~cm}$ de comprimento, com corte em bisel na base e reto acima da última gema axilar, com cinco gemas axilares e sem folhas. Após o preparo as estacas foram submetidas ao tratamento fitossanitário com hipoclorito de sódio a $0,5 \%(\mathrm{v} / \mathrm{v})$ por $15 \mathrm{~min}$ e enxaguadas em água corrente durante 5 minutos.

No experimento sobre a influência dos reguladores vegetais no enraizamento, os tratamentos foram compostos pelas concentrações 0, 500, 1.000, 2.000, 3.000 e $4.000 \mathrm{mg} \mathrm{L}^{-1}$ de ácido naftaleno acético (NAA) e de ácido indolbutírico (IBA). As bases das estacas foram imersas por 15 segundos em soluções hidroalcoólica ( $50 \%$ de álcool etílico $95 \%$ PA e $50 \%$ de água destilada) contendo NAA ou IBA. As estacas foram imediatamente colocadas para enraizamento em bandejas plásticas perfuradas com dimensões $30 \times 22 \times 7 \mathrm{~cm}$, contendo uma camada de $6 \mathrm{~cm}$ de vermiculita de granulometria média como substrato. O experimento foi conduzido em delineamento experimental inteiramente casualizado, com seis tratamentos e quatro repetições, sendo a unidade experimental constituída por 15 estacas.

No experimento sobre a influência de substratos no enraizamento da erva-baleeira, os tratamentos foram compostos de vermiculita expandida (granulometria média da Eucatex Química e Mineral LTDA) + casca de arroz parcialmente carbonizada (proporção de 1:1); vermiculita expandida (granulometria média da Eucatex Química e Mineral LTDA); substrato orgânico comercial para hortaliça (Tropstrato $\mathrm{HT}^{\circledR}$ que é composto por casca de pinus, turfa, vermiculita expandida, enriquecido com macronutrientes e micronutrientes, em proporções não divulgadas); areia; solo + compostagem (constituído de esterco bovino e resíduo de origem vegetal, em proporções não divulgadas) (proporção de 1:1).

Após o preparo das estacas, as bases das mesmas foram tratadas com IBA em solução hidroalcoólica (50\% de álcool etílico 95\% PA e $50 \%$ de água destilada) por 15 segundos, na concentração de $2.000 \mathrm{mg} \mathrm{L}^{-1}$, sendo posteriormente colocadas para enraizar em bandejas plásticas perfuradas com dimensões $30 \times 22 \times 7 \mathrm{~cm}$, contendo uma camada de $6 \mathrm{~cm}$ dos substratos avaliados. O experimento foi conduzido no delineamento experimental inteiramente casualizado, com cinco tratamentos e cinco repetições, sendo a unidade experimental constituída de 15 estacas.

Os experimentos foram conduzidos em casa de vegetação com nebulização intermitente a cada três horas, com duração de 15 minutos durante o período das 7 às 19 horas. Após 90 dias foram avaliadas as seguintes variáveis: porcentagem de estacas enraizadas (estacas que apresentavam primórdio radicial a partir de $0,3 \mathrm{~cm}$ de comprimento); porcentagem de estacas mortas (estacas que apresentavam mortas e sem emissão de raiz); porcentagem de estacas vivas com calos (estacas que apresentavam primórdio radicial com cerca de $0,1 \mathrm{~cm}$ de comprimento com coloração branca), de estacas mortas com calos (estacas que apresentavam primórdio radicial com cerca de 0,1 $\mathrm{cm}$ de comprimento com coloração preta), número de raízes formadas por estaca (número de raízes a partir de $0,3 \mathrm{~cm}$ de comprimento) e comprimento das três maiores raízes $(\mathrm{cm})$.

Para as análises estatísticas, os dados em porcentagem foram transformados em arcsen $\sqrt{x / 100}$. Para o experimento das diferentes concentrações de ácido naftaleno acético e de ácido indolbutírico foram realizadas regressão polinominal, a fim de verificar a resposta das variáveis em função do aumento da concentração de cada auxina. Para o experimento dos diferentes substratos as variáveis avaliadas foram submetidas a análise estatísticas através de programa estatístico SISVAR (Ferreira, 2008), realizando-se a análise variância e o teste de Tukey a $5 \%$ de probabilidade, para a comparação das médias. Os dados obtidos nas variáveis número de raízes formadas por estaca e o comprimento das três maiores raízes $(\mathrm{cm})$, no experimento sobre a influência de substratos no enraizamento da ervabaleeira, foram transformados em $\sqrt{x+0,5}$.

\section{RESULTADOS E DISCUSSÃO}

No experimento que avaliou as diferentes concentrações dos reguladores vegetais foi possível verificar que para a porcentagem de estacas enraizadas os tratamentos acima de $1.000 \mathrm{mg}$ $\mathrm{L}^{-1}$ apresentaram os melhores resultados para $\mathrm{O}$ ácido indolbutírico (IBA) (Figura 1). Para o ácido 
naftaleno acético (NAA) verificou-se que $500 \mathrm{mg}$ $\mathrm{L}^{-1}$ foi a melhor a concentração, entretanto acima desse valor verifica-se diminuição na porcentagem de enraizamento de estacas de erva-baleeira (Figura 1). Concentrações excessivas de auxinas podem inibir o desenvolvimento das raízes e brotações, causar o amarelecimento e queda das folhas, necrose ou até ocasionarem a morte das estacas, isso ocorre por existir o ponto máximo da dose que é o ponto que propicia um aumento no enraizamento (Alcantara et al., 2010).

A aplicação dos reguladores vegetais em uma concentração ótima irá estimular o crescimento e diferenciação dos tecidos, causando aumento na porcentagem de enraizamento, que irá depender do nível endógeno de hormônios, combinado com outros promotores do enraizamento (Hartmann et al., 2002). Em estudos com jambolão (Syzygium cumini) verificou-se que a maior porcentagem de enraizamento ocorreu com aplicação de $1.000 \mathrm{mg} \mathrm{L}^{-1}$ de IBA e NAA e que concentrações acima de 1.000 $\mathrm{mg} \mathrm{L}^{-1}$ inibiram a formação de raízes (Alcantara et al., 2010).

As porcentagens máximas de enraizamento foram obtidas nas concentrações de $2000 \mathrm{mg} \mathrm{L}^{-1}$ de IBA $(53,3 \%)$ e $500 \mathrm{mg} \mathrm{L}^{-1}$ de NAA $(51,1 \%)$. Lameira et al. (1997) verificaram $68 \%$ de enraizamento e maior número de raízes, utilizando IBA na concentração de $250 \mathrm{mg} \mathrm{L}^{-1} \mathrm{em}$ miniestacas de erva-baleeira com $10 \mathrm{~cm}$ de comprimento e coletada a $5 \mathrm{~cm}$ da região apical. A porcentagem de enraizamento observada por Lameira et al. (1997), é maior que a do presente trabalho, provavelmente se deve ao fato de que as estacas utilizadas por esses autores foram coletadas de plantas matrizes mais jovens, três anos de idade, quando comparadas a matriz utilizada no presente trabalho, dez anos de idade. A idade da planta matriz é um fator importante no enraizamento, visto que as estacas retiradas de plantas em estádio juvenil apresentam maior capacidade de formar raízes adventícias do que aquelas retiradas de plantas adultas (Fachinello et al., 2005).

Com a utilização do IBA foi verificada porcentagem de enraizamento superior ao NAA, exceto para a dose de $500 \mathrm{mg} \mathrm{L}^{-1}$. Resultados semelhantes foram observados por Husen \& Pal (2007) testando duas concentrações $(2.000$ e $4.000 \mathrm{mg} \mathrm{L}^{-1}$ ) dos reguladores vegetais em estacas coletadas de brotações medianas de teca (Tectona grandis), onde foi observado melhor resposta ao IBA quando comparado ao NAA. Goulart et al. (2008), avaliando a eficiência dos reguladores vegetais,

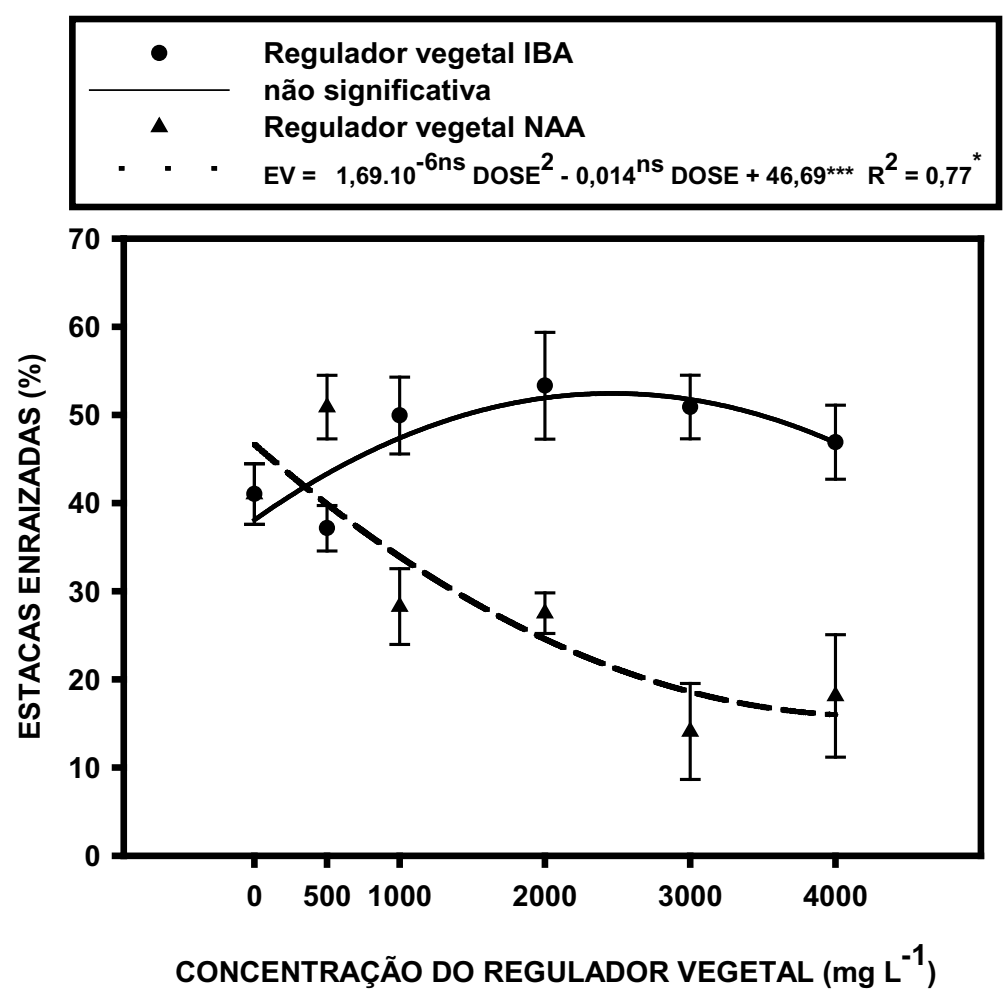

FIGURA 1. Porcentagem de estacas enraizadas de erva-baleeira (Varronia curassavica), em função das concentrações de ácido indolbutírico (IBA) e do ácido naftaleno acético (NAA) (Montes Claros, MG, 2012). * significativo pelo teste t-Student a $10 \%$ de probabilidade; ns: não significativo; $R^{2}=$ coeficiente de determinação. As barras indicam os valores de erro padrão da média e a sobreposição destas denota a ausência de diferenças entre as médias dos tratamentos. 
IBA e NAA, no enraizamento de miniestacas de quatro clones de Eucalyptus grandis x E. urophylla, observaram que a utilização do IBA nas concentrações entre 500 e $2.000 \mathrm{mg} \mathrm{L}^{-1}$ mostrouse mais eficiente do que o NAA. Em contrapartida, Alcantara et al. (2010) verificaram melhor resposta ao enraizamento de jambolão (Syzygium cumini) com a utilização do NAA em praticamente em todas as concentrações testadas.

As concentrações do IBA apresentaram a menor porcentagem de estacas mortas (Figura 2), já o uso do NAA, nas concentrações superiores a $500 \mathrm{mg} \mathrm{L}^{-1}$, proporcionaram a maior porcentagem de estacas mortas. Essa resposta ocorreu, possivelmente, porque o NAA é uma auxina mais tóxica que o IBA, devendo por tanto ser utilizada em menores concentrações (Fachinello et al., 2005). Althaus et al. (2007) avaliando a influência do NAA, nas concentrações 0 e $5000 \mathrm{mg} \mathrm{L}^{-1}$, e os substratos vermiculita e Plantmax $\mathrm{HA} \otimes$ no enraizamento de estacas caulinares de Jasminum mesnyi, verificaram maior porcentagem de estacas mortas quando usada a concentração de $5.000 \mathrm{mg} \mathrm{L}^{-1}$ de NAA.

A porcentagem de estacas vivas e mortas com calos não diferiu estatisticamente entre as concentrações dos reguladores vegetais em estudo (Figuras 3A e 3B). Na maioria das estacas a formação de calos ocorreu na base e na região lateral das mesmas. Dentre as estacas vivas com calos foi observado que a formação de calos foi menor que $40 \%$ quando tratadas com o NAA. Segundo Hartmann et al. (2002) os calos são constituídos por muitas células parenquimatosas resultantes dos novos centros meristemáticos formados próximos aos feixes vasculares junto ao floema, através dos quais as raízes emergem. Sendo assim, a formação das raízes adventícias e dos calos são processos independentes, e sua ocorrência simultânea se explica pelo fato de ambos envolverem o processo de divisão celular e dependerem de condições ambientais favoráveis. Desta forma, observa-se que a formação de calos também não foi favorecida pelo NAA, bem como, a porcentagem do enraizamento.

Analisando o número de raízes formadas por estaca e o comprimento médio das três maiores raízes, observou-se que os valores obtidos nas maiores concentrações de IBA foram significativamente superior à dose $0 \mathrm{mg} \mathrm{L}^{-1}$, com ajuste de regressão linear (Figura $3 \mathrm{C}$ e $3 \mathrm{D}$ ). As concentrações 500 e $1.000 \mathrm{mg} \mathrm{L}^{-1}$ de NAA favoreceram maior número de raízes por estaca
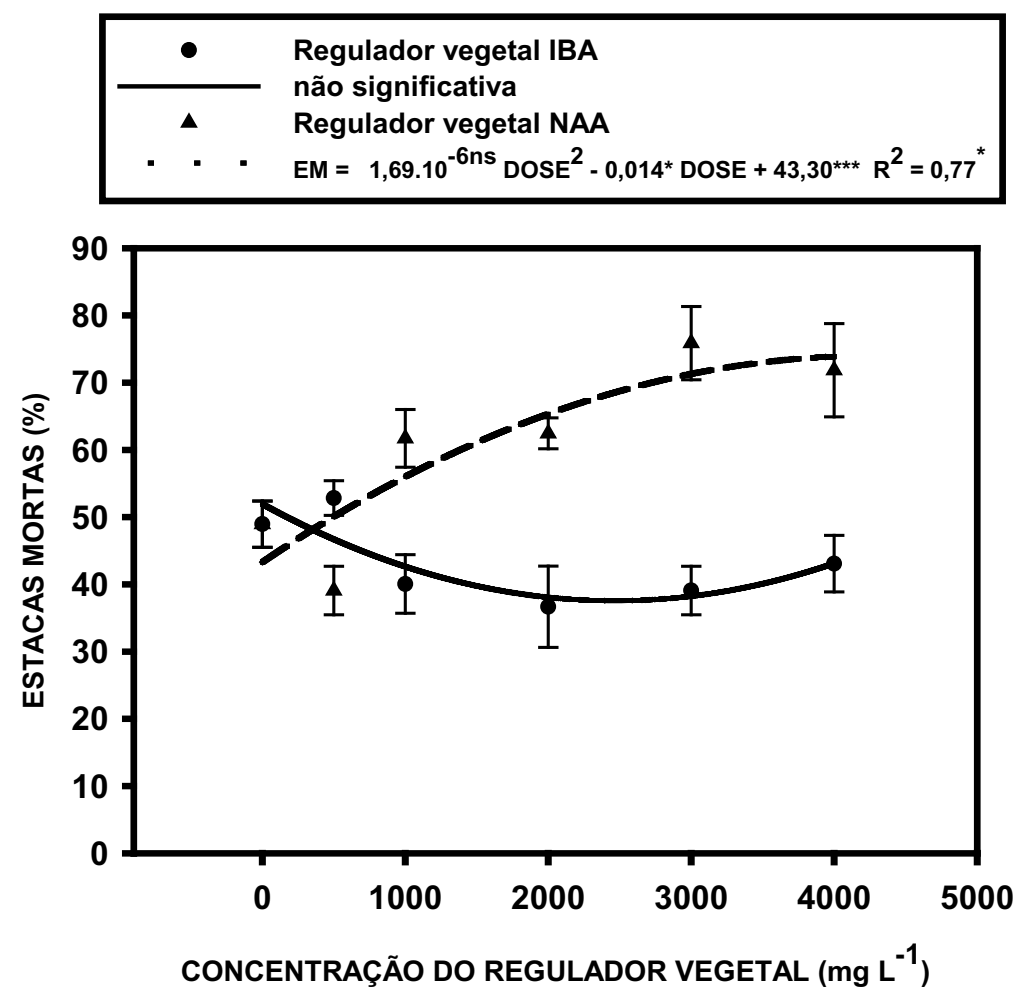

FIGURA 2. Porcentagem de estacas mortas de erva-baleeira (Varronia curassavica), em função das concentrações de ácido indolbutírico (IBA) e do ácido naftaleno acético (NAA) (Montes Claros, MG, 2012). * significativo pelo teste t-Student a $10 \%$ de probabilidade; ns: não significativo; $R^{2}$ = coeficiente de determinação. As barras indicam os valores de erro padrão da média e a sobreposição destas denota a ausência de diferenças entre as médias dos tratamentos. 

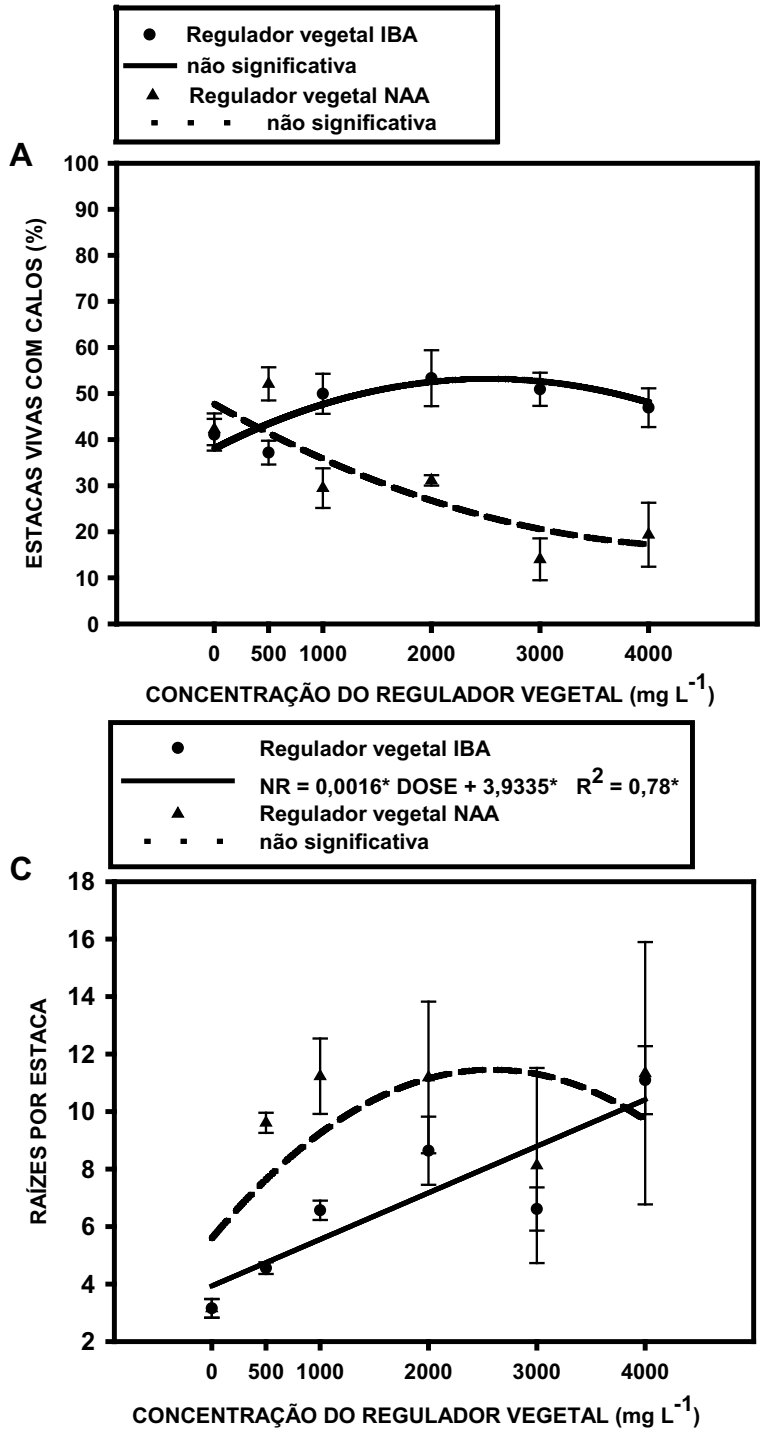
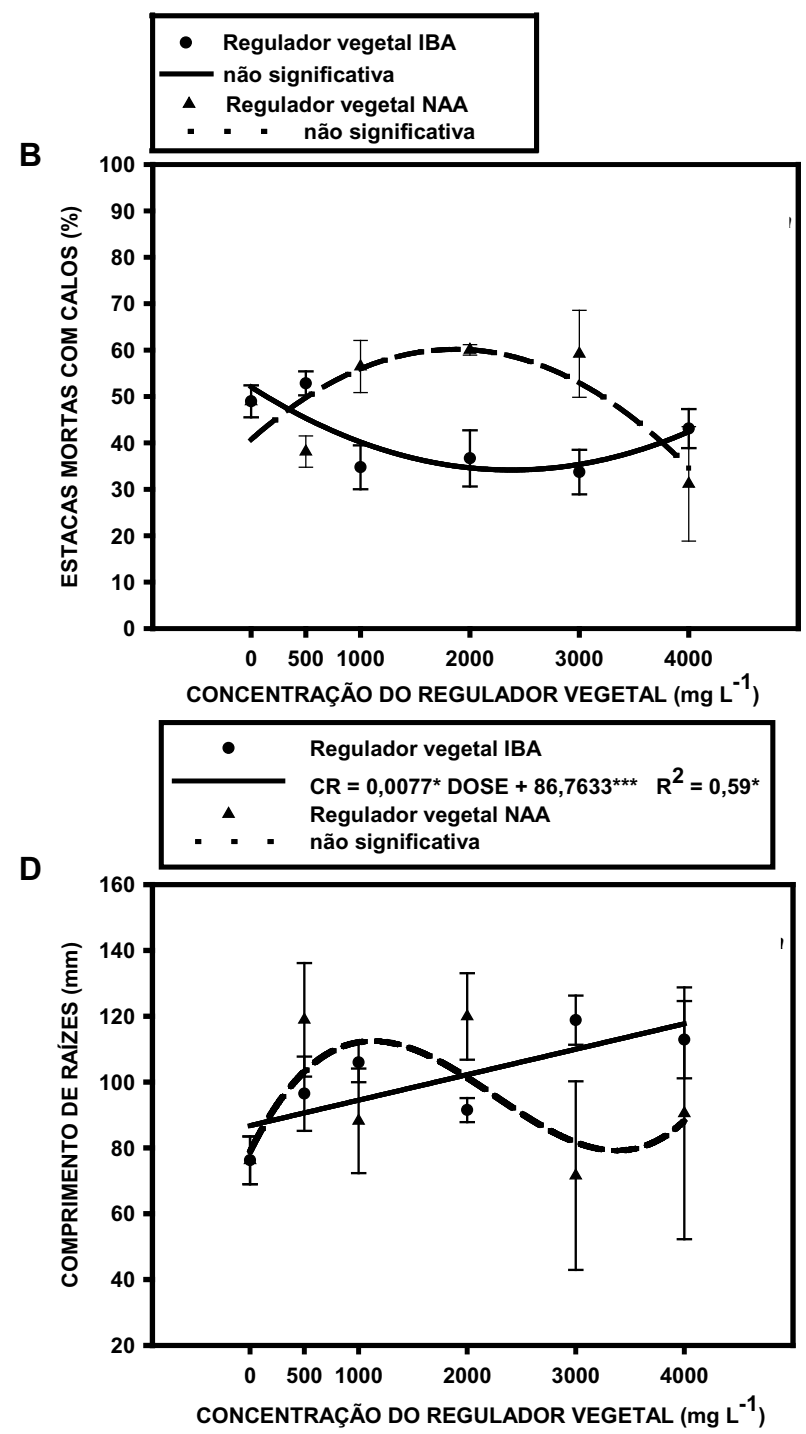

FIGURA 3. Porcentagem de estacas mortas com calos (A), porcentagem de estacas vivas com calos (B), número médio de raízes por estacas $(C)$ e comprimento médio das três maiores raízes $(D)$ de estacas de erva-baleeira (Varronia curassavica), em função das concentrações de ácido indolbutírico (IBA) e do ácido naftaleno acético (NAA) (Montes Claros, MG, 2012). ${ }^{*}$ significativo pelo teste t-Student a $10 \%$ de probabilidade; $R^{2}=$ coeficiente de determinação. As barras indicam os valores de erro padrão da média e a sobreposição destas denota a ausência de diferenças entre as médias dos tratamentos.

sendo 9,61 e 11,26 raízes, respectivamente, quando comparado com o IBA. No entanto, com a utilização do NAA foi observado as menores porcentagens de enraizamento.

Resultados semelhantes foram observados em estacas de jambolão (Syzygium cumini) testadas com cinco concentrações $(0,500,1.000,1.500$ e $2.000 \mathrm{mg} \mathrm{L}^{-1}$ ) de IBA e NAA, onde o maior número de raízes formadas por estaca e o comprimento médio das três maiores raízes foram observados na concentração $1.500 \mathrm{mg} \mathrm{L}^{-1}$ de NAA, sendo essa a concentração que apresentou menor porcentagem de enraizamento (Alcantara et al., 2010). Segundo os mesmos autores, o regulador vegetal pode acelerar o metabolismo normal e aumentar o número de primórdios radiciais, mesmo que não aumente a porcentagem de enraizamento.

No experimento sobre a influência de substratos no enraizamento da erva-baleeira foi observado diferenças significativas, para todas as variáveis avaliadas, entre o substrato vermiculita com casca de arroz carbonizada e o substrato solo + compostagem.

$\mathrm{Na}$ avaliação de porcentagem das estacas 
TABELA 1. Porcentagens de estacas enraizadas (EE), de estacas mortas (EM), de estacas vivas com calo (EVC), de estacas mortas com calo (EMC), número de raízes por estacas (NRE) e comprimento das três maiores raízes (CRE) formadas por estacas de erva-baleeira (Varronia curassavica), para os cinco substratos avaliados (Montes Claros, MG, 2012).

\begin{tabular}{lllllll}
\hline Substratos & EE $(\%)$ & EM (\%) & EVC (\%) & EMC (\%) & NRE & CRE (mm) \\
\hline $\begin{array}{l}\text { Vermiculita+casca de } \\
\text { arroz parcialmente }\end{array}$ & $31,11 \mathrm{a}$ & $62,49 \mathrm{~b}$ & $31,89 \mathrm{a}$ & $23,06 \mathrm{a}$ & $2,51 \mathrm{a}$ & $172,10 \mathrm{a}$ \\
$\begin{array}{l}\text { carbonizada } \\
\text { Vermiculita }\end{array}$ & $22,63 \mathrm{a}$ & $67,36 \mathrm{ab}$ & $22,83 \mathrm{a}$ & $43,08 \mathrm{a}$ & $1,65 \mathrm{ab}$ & $195,62 \mathrm{a}$ \\
Substrato comercial & $14,91 \mathrm{ab}$ & $74,18 \mathrm{ab}$ & $15,81 \mathrm{ab}$ & $28,50 \mathrm{a}$ & $1,27 \mathrm{ab}$ & $60,46 \mathrm{~b}$ \\
Areia lavada & $17,56 \mathrm{ab}$ & $71,66 \mathrm{ab}$ & $18,34 \mathrm{ab}$ & $40,86 \mathrm{a}$ & $1,08 \mathrm{ab}$ & $13,26 \mathrm{bc}$ \\
Solo+compostagem & $0,00 \mathrm{~b}$ & $100,00 \mathrm{a}$ & $0,00 \mathrm{~b}$ & $0,00 \mathrm{~b}$ & $0,00 \mathrm{~b}$ & $0,00 \mathrm{c}$ \\
\hline C.V. $(\%)$ & 47,35 & 9,81 & 48,14 & 37,39 & 29,40 & 43,12 \\
\hline
\end{tabular}

Médias seguidas pela mesma letra minúscula na vertical, não diferem significativamente pelo Teste de Tukey a $5 \%$ de probabilidade Os dados do número de raízes por estacas (NRE) e comprimento das três maiores raízes (CRE) foram transformados em $\sqrt{x+0,5}$.

enraizadas de erva-baleeira, as maiores médias foram observadas nos substratos vermiculita com casca de arroz carbonizada e vermiculita, sendo de $31,11 \%$ e $22,63 \%$, respectivamente (Tabela 1). Resultados semelhantes foram observados para porcentagem de enraizamento de estacas de Mikania glomerata e M. laevigata (Lima et al., 2003), Calliandra selloi e C. tweediei (Lima et al., 2006) e Jasminum mesnyi (Althaus et al., 2007) quando utilizaram vermiculita ou a casca de arroz carbonizada. No experimento com Ginkgo biloba, Bitencourt et al. (2010), observaram que a concentração de IBA não influenciou na porcentagem de estacas enraizadas quando se utilizou casca de arroz carbonizada, sendo que o substrato influenciou positivamente no enraizamento da espécie.

Souza et al. (2006) avaliando o enraizamento de estacas de maracujazeiro azedo (Passiflora edulis) produzidas com diferentes porcentagens de mistura de vermiculita e casca de arroz carbonizada, verificaram máxima resposta de enraizamento em estacas plantadas em substrato com a composição de $50 \%$ de vermiculita e $50 \%$ de casca de arroz carbonizada.

A casca de arroz carbonizada apresenta menor densidade, maior porcentagem de macroporos e elevada resistência à decomposição, conferindo ao substrato maior aeração e drenagem (Lone et al., 2010). A vermiculita também apresenta elevada porcentagem de macroporos, apesar de apresentar uma densidade menor que a casca de arroz carbonizada, no entanto, a mesma apresenta uma boa retenção de umidade, evitando a desidratação das estacas (Mauad et al., 2004, Souza et al., 2006).
A mistura dos dois materiais permite atingir níveis intermediários de retenção de água, de aeração e de disponibilidade de água nos substratos, favorecendo o enraizamento de estacas (Souza et al., 2006).

O substrato solo + compostagem foi o que se destacou entre os substratos avaliados na porcentagem de estacas mortas, mostrando que este substrato foi o menos eficiente para propagação de estacas de erva-baleeira, possivelmente, devido a maior retenção de água na bandeja, o que reduziu a aeração na base das estacas, condição essa desfavorável para o crescimento radicial. Resultado semelhante foi observado por Mauad et al. (2004) para o enraizamento de estacas de azaléia (Rhododendron simsii), onde o substrato húmus com maior retenção de água proporcionou maior porcentagem de estacas mortas, quando comparado com os substratos areia e casca de arroz carbonizada.

Para o número médio de raízes por estacas foi verificada diferença estatística entre os substratos testados (Tabela 1), sendo que o tratamento vermiculita com casca de arroz parcialmente carbonizada foi o que apresentou a maior média. Os demais substratos não diferiram desse substrato e nem no substrato solo com compostagem, que apresentou a menor média de número de raízes por estacas. O número de raízes por estacas é um fator importante a ser considerado, pois o maior número de raízes permitirá maior chance de sucesso da muda no campo, por apresentar desenvolvimento mais rápido e vigoroso (Reis et al., 2000).

Os substratos vermiculita com casca de arroz parcialmente carbonizada e vermiculita

Rev. Bras. PI. Med., Campinas, v.16, n.2, p.262-270, 2014. 
proporcionaram maior comprimento de raiz das estacas em relação aos demais substratos. Lone et al. (2010) e Mauad et al. (2004) também relataram que a casca de arroz carbonizada foi o substrato que proporcionou maior comprimento de raiz nas estacas de azaleia (Rhododendron simsii), possivelmente em função da menor densidade e maior porcentagem de macroporos, o que possivelmente facilita $o$ escoamento do excesso de água favorecendo o desenvolvimento radicial. De acordo com os resultados observados, a erva-baleeira parece ser uma planta exigente em aeração e umidade no substrato para o enraizamento da estaca.

As estacas de erva-baleeira nos experimentos do presente estudo não apresentaram elevadas porcentagens de enraizamento, possivelmente, alguns fatores internos e externos da planta matriz e ou das estacas podem ter influenciado. Os fatores internos estão relacionados com as condições fisiológicas da planta matriz, o potencial genético de enraizamento a idade da planta ou das estacas, o tipo de estaca, a época de coleta, a sanidade da planta, o balanço hormonal e a possibilidade de oxidação de compostos fenólicos. A temperatura, a luz, a umidade, o substrato e os condicionamentos que as estacas são submetidas são os fatores externos. A interação entre os fatores internos e externos é utilizado para elucidar as causas do enraizamento (Fachinello et al., 2005; Nienow et al., 2010).

Deste modo, a realização de futuros trabalhos direcionados a obtenção de respostas ao comportamento do enraizamento de estacas de erva-baleeira mediante diferentes tipos de estacas, matriz com diferentes idades, época da coleta, temperatura e luz tornam-se relevantes para a pesquisa.

\section{CONCLUSÕES}

O enraizamento de estacas de ervabaleeira é viável, pois as estacas semi-lenhosa permite alcançar porcentagem próximo de 52,5\%.

0 regulador vegetal ideal para 0 enraizamento da espécie é o ácido indolbutírico (IBA) na concentração de $2.000 \mathrm{mg} \mathrm{L}^{-1}$, enquanto o ácido naftaleno acético (NAA) não é recomendado para a indução radicial em estacas da erva-baleeira.

O substrato vermiculita com casca de arroz carbonizada na proporção de 1:1 proporcionou maior porcentagem de enraizamento nas estacas da erva-baleira que o substrato solo + compostagem; os demais substratos não diferenciaram entre si.

\section{REFERÊNCIA}

ALCANTARA, G.B. et al. Efeito dos ácidos naftaleno e indolbutírico no enraizamento de estacas de jambolão [Syzygium cumini (L.) Skeels]. Revista Brasileira de Plantas Medicinais, v. 12, n. 3, p. 317-321, 2010.

ALTHAUS, M.M. et al. Influência do ácido naftaleno acético e dois tipos de substrato no enraizamento de estacas de jasmim-amarelo. Revista Ciência Agronômica, v. 38, n. 3, p. 322-326, 2007.

BITENCOURT, J. et al. Estaquia de Ginkgo biloba L. utilizando três substratos. Revista Brasileira de Plantas Medicinais, v. 12, n. 2, p. 135-140, 2010.

CAMARGO, P.R.D.; VIEIRA, E.L. Aplicações de reguladores vegetais na agricultura tropical. Guaíba: Agropecuária, 2001.

CARVALHO Jr., P.M. et al. Chemical composition and antimicrobial activity of the essential oil of Cordia verbenacea D. C. Journal of Ethnopharmacology, v. 95, n. 2-3, p. 297-301, 2004.

FACHINELLO, J.C.; HOFFMANN, A.; NACHTIGAL, J.C. (Eds). Propagação de plantas frutíferas. Brasília: Embrapa Informações Tecnológicas, 2005. 221 p.

FERNANDES, E.S. et al. Anti-inflammatory effects of compounds alpha-humulene and (-)-trans-caryophyllene isolated from the essential oil of Cordia verbenacea. European Journal of Pharmacology, Amsterdam, v. 569, n. 3, p. 228-236, 2007.

FERREIRA, D. F. SISVAR: um programa para análises e ensino de estatística. Revista Científica Symposium, Lavras, v. 6, n. 2, p. 36-41, 2008.

GOULART, P.B. et al. Efeito dos reguladores de crescimento AIB e ANA no enraizamento de miniestacas de clones de Eucalyptus grandis X Eucalyptus urophylla. Revista Árvore, v. 32, n. 6, p. 1051-1058, 2008.

HARTMANN, H.T., KESTER, D.T. DAVIES JR., F.T.; GENEVE, R.L. Plant propagation: principles e practices. 7.ed. New Jersey: Prentice Hall, 2002.

HUSEN, A.; PAL, M. Effect of branch position and auxin treatment on clonal propagation of Tectona grandis Linn. f. New Forests, v. 34, n. 3, p. 223-233, 2007.

LAMEIRA, O.A. et al. Enraizamento de miniestacas de erva-baleeira. Horticultura brasileira, v. 15, n. 2, p. 114-116, 1997.

LIMA, N.P. et al. Produção de mudas por estaquia de duas espécies de guaco. Horticultura brasileira, v. 21, n. 1, p. 106-109, 2003.

LIMA, D.M. et al. Substrato e concentrações de ácido naftaleno acético no enraizamento de estacas semilenhosas de Calliandra selloi e Calliandra tweediei. Scientia Agraria, v. 7, n. 1-2, p. 105-111, 2006.

LONE, A.B. et al. Enraizamento de estacas de azaleia (Rhododendron simsii Planch.) no outono em AIB e diferentes substrato. Ciência Rural, v. 40, n. 8, p. 1720-1725, 2010.

LORENZI, H.; MATOS, F.J.A. Plantas medicinais no Brasil: nativas e exóticas. 2.ed. Nova Odessa: Plantarum, 2008. 544p.

MAUAD, M. et al. Enraizamento de estacas de azaleia tratadas com concentrações de ANA em diferentes substratos. Ciência e agrotecnologia, v. 28, n. 4, p.771-777, 2004.

MEDEIROS, R. et al. Effect of two active compounds 
obtained from the essential oil of Cordia verbenacea on the acute inflammatory responses elicited by LPS in the rat paw. British Journal of Pharmacology, v. 151, n. 5, p. 618-627, 2007.

MICHIELIN, E.M.Z. et al. Chemical composition and antibacterial activity of Cordia verbenacea extracts obtained by different methods. Bioresource Technology, v. 100, n. 24, p. 6615-6623, 2009.

NIENOW, A.A. et al. Enraizamento de estacas de quaresmeira em duas épocas e concentrações de ácido indolbutírico. Revista Brasileira de Agrociência, v. 16, n. 1-4, p. 139-142, 2010

PASSOS, G.F. et al. Antiinflammatory and anti-allergic properties of the essential oil and active compounds from
Cordia verbenacea. Journal of Ethnopharmacology, v. 110, n. 2, p. 323-333, 2007.

REIS, J.M.R. et al. Efeito do estiolamento e do ácido indolbutírico no enraizamento de estacas do porta-enxerto Pyrus calleryana Dcne. Ciência e Agrotecnologia, v. 24, n. 4, p. 931-938, 2000.

SOUZA, P.V.D. et al. Efeito da composição do substrato no enraizamento de estacas de maracujazeiro azedo. Revista Brasileira Fruticultura, v. 28, n. 2, p. 276279, 2006.

VAZ, A.A.A. et al. Biomassa e composição química de genótipos melhorados de espécies medicinais cultivadas em quatro municípios paulista. Pesquisa agropecuária brasileira, v. 41, n. 5, p. 869-872, 2006. 